\title{
On a New Stability Problem of Radical $n$ th-Degree Functional Equation by Brzdęk's Fixed-Point Method
}

\author{
Dongseung Kang $\mathbb{D}^{1}$ and Hoewoon B. Kim $\mathbb{D}^{2}$ \\ ${ }^{1}$ Mathematics Education, Dankook University, 152 Jukjeon, Suji, Yongin, Gyeonggi 16890, Republic of Korea \\ ${ }^{2}$ Department of Mathematics, Oregon State University, Corvallis, OR 97331, USA
}

Correspondence should be addressed to Hoewoon B. Kim; khoe77@gmail.com

Received 28 February 2019; Revised 7 May 2019; Accepted 10 June 2019; Published 25 June 2019

Guest Editor: Pedro Garrancho

Copyright (C) 2019 Dongseung Kang and Hoewoon B. Kim. This is an open access article distributed under the Creative Commons Attribution License, which permits unrestricted use, distribution, and reproduction in any medium, provided the original work is properly cited.

\begin{abstract}
In this paper, we introduce the radical $n$ th-degree functional equation of the form $f\left(\sqrt[n]{x^{n}+y^{n}}\right)=f(x)+f(y)$ with a positive integer $n$, discuss its general solutions, and prove new Hyers-Ulam-type stability results for the equation by using Brzdęk's fixedpoint method.
\end{abstract}

\section{Introduction}

In mathematical analysis, we often deal with the following question: Under what conditions should a mathematical object satisfying certain properties approximately be close to the one satisfying the properties exactly? If we consider a functional equation, then we can ask the same question: When could the approximates to a functional equation be close to the solution of the equation? Then, there would be an issue of error estimation between the approximates and the solution of a functional equation that we will investigate in this paper, not only the process of finding the solution of the equation. Such a fundamental question for functional equations led to the theory of Hyers-Ulam stability.

The Hyers-Ulam stability problem of functional equations was first raised in a talk at the University of Wisconsin. In 1940, a Polish-American mathematician called Ulam [1] proposed the stability problem of a group homomorphism: When does a linear mapping near an approximately linear mapping exist?

In 1941, Hyers [2] gave the first, affirmative, and partial solution to Ulam's question with an additive function, $f(x+$ $y)=f(x)+f(y)$, in Banach spaces as in the following theorem.
Theorem 1. Assume that $E_{1}$ and $E_{2}$ are Banach spaces. If a function $f: E_{1} \longrightarrow E_{2}$ satisfies the inequality

$$
\|f(x+y)-f(x)-f(y)\| \leq \epsilon
$$

for some $\epsilon \geq 0$ and for all $x, y \in E_{1}$, then the limit $a(x)=$ $\lim _{n \rightarrow \infty} 2^{-n} f\left(2^{n} x\right)$ exists for each $x \in E_{1}$ and $a: E_{1} \longrightarrow$ $E_{2}$ is the unique additive function (or the solution to Cauchy function) such that

$$
\|f(x)-a(x)\| \leq \epsilon
$$

for any $x \in E_{1}$. Moreover, if $f(t x)$ is continuous in $t$ for each fixed $x \in E_{1}$, then $a$ is linear.

In 1950, Aoki [3] provided a generalization of Hyers' theorem with a positive monotone nondecreasing symmetric function of $\|x\|$ and $\|y\|$ involving a power $0 \leq p<0$, where Theorem 1 is a special case when $p=0$. Also see $[4,5]$ for the generalization in terms of bordering transformations and an approximately linear mapping of addition and scalar multiplication, respectively.

For the last decades, stability problems of various functional equations, not only linear case, have been extensively 
investigated and generalized by many mathematicians (see [6-10]). One of the functional equations of the form

$$
f\left(\sqrt{x^{2}+y^{2}}\right)=f(x)+f(y)
$$

is called a radical quadratic functional equation and every solution to this functional equation is referred to as a radical quadratic function or mapping. The question of existence and uniqueness of the general solution of the functional equation (3) was answered by Brzdęk (see [11], p.196); i.e., a real-valued function $f: \mathbb{R} \longrightarrow \mathbb{R}$ ( $\mathbb{R}$ stands for the set of real numbers) is a solution to (3) if and only if $f(x)=L\left(x^{2}\right), x \in \mathbb{R}$, where the function $L: \mathbb{R} \longrightarrow \mathbb{R}$ is additive; i.e., it satisfies $L(x+y)=L(x)+L(y)$ for all $x, y \in \mathbb{R}$. Gordji and Parviz [12] and Cho et al. [13] investigated the Hyers-Ulam stability problems of the functional equations of the radical type as (3). In particular, Baker [14] applied for the first time a variant of Banach's fixed-point theorem to obtain the stability of a functional equation in a single variable. For the applications and surveys of this approach in detail, see [15-17] where the paper [16] is an updated version of survey [15]. Moreover, Brzdęk and Ciepliński [18] introduced the following existence theorem of the fixed point for nonlinear operator in metric spaces.

Theorem 2 (see [18]). Let $X$ be a nonempty set, $(Y, d)$ a complete metric space, and $\Lambda: Y^{X} \longrightarrow Y^{X}$ a nondecreasing operator satisfying the hypothesis

$$
\lim _{n \longrightarrow \infty} \Lambda \delta_{n}=0
$$

for every sequence $\left\{\delta_{n}\right\}_{n \in \mathbb{N}}$ with $\lim _{n \rightarrow \infty} \delta_{n}=0$ in $Y^{X}$.

Suppose that $\mathscr{T}: Y^{X} \longrightarrow Y^{X}$ is an operator satisfying the inequality

$$
\begin{aligned}
d(\mathscr{T} \varepsilon(x), \mathscr{T} \mu(x)) \leq \Lambda(\triangle(\varepsilon, \mu))(x), & \\
& \varepsilon, \mu \in Y^{X}, x \in X
\end{aligned}
$$

where $\triangle:\left(Y^{X}\right)^{2} \longrightarrow \mathbb{R}_{+}^{X}$ is a mapping which is defined by

$$
\triangle(\varepsilon, \mu)(x):=d(\varepsilon(x), \mu(x))
$$

$$
\text { for } \varepsilon, \mu \in Y^{X}, x \in X
$$

If there exist functions $\varepsilon: X \longrightarrow \mathbb{R}_{+}$and $\phi: X \longrightarrow Y$ such that

$$
d(\mathscr{T} \phi(x), \phi(x)) \leq \varepsilon(x)
$$

and

$$
\varepsilon^{*}(x):=\sum_{n \in \mathbb{N}_{0}}\left(\Lambda^{n} \varepsilon\right)(x)<\infty
$$

for all $x \in X$, then the limit

$$
\lim _{n \longrightarrow \infty}\left(\mathscr{T}^{n} \phi\right)(x)
$$

exists for each $x \in X$. Moreover, the function $\phi \in Y^{X}$ defined by

$$
\psi(x):=\lim _{n \rightarrow \infty}\left(\mathscr{T}^{n} \phi\right)(x)
$$

is a fixed point of $\mathscr{T}$ with

$$
d(\phi(x), \psi(x)) \leq \varepsilon^{*}(x)
$$

for all $x \in X$.

Then they used this result to prove the stability problem of functional equations in non-Archimedean metric spaces and obtained the fixed-point results in arbitrary metric spaces. Another version of the Brzdęk fixed-point method was also obtained from Theorem 2 (see [19] for details) as follows.

Theorem 3 (see [19]). Let $X$ be a nonempty set, $(Y, d)$ a complete metric space, and $f_{1}, f_{2}: X \longrightarrow X$ given mappings. Suppose that $\mathscr{T}: Y^{X} \longrightarrow Y^{X}$ and $\Lambda: \mathbb{R}_{+}^{X} \longrightarrow \mathbb{R}_{+}^{X}$ are two operators satisfying the following conditions:

$$
\begin{aligned}
d(\mathscr{T} \xi(x), \mathscr{T} \mu(x)) \leq & d\left(\xi\left(f_{1}(x)\right), \mu\left(f_{1}(x)\right)\right) \\
& +d\left(\xi\left(f_{2}(x)\right), \mu\left(f_{2}(x)\right)\right)
\end{aligned}
$$

and

$$
\Lambda \delta(x):=\delta\left(f_{1}(x)\right)+\delta\left(f_{2}(x)\right)
$$

for all $\xi, \mu \in Y^{X}, \delta \in \mathbb{R}_{+}^{X}$, and $x \in X$. If there exist $\varepsilon: X \longrightarrow$ $\mathbb{R}_{+}$and $\phi: X \longrightarrow Y$ such that

$$
\begin{aligned}
d(\mathscr{T} \phi(x), \phi(x)) & \leq \varepsilon(x) \\
\varepsilon^{*}(x) & :=\sum_{n=0}^{\infty}\left(\Lambda^{n} \varepsilon\right)(x)<\infty
\end{aligned}
$$

for all $x \in X$, then the limit $\lim _{n \rightarrow \infty}\left(\mathscr{T}^{n} \phi\right)(x)$ exists for each $x \in X$. Moreover, the function $\psi(x):=\lim _{n \rightarrow \infty}\left(\mathscr{T}^{n} \phi\right)(x)$ is a fixed point of $\mathscr{T}$ with

$$
d(\phi(x), \psi(x)) \leq \varepsilon^{*}(x)
$$

for all $x \in X$.

Recently, Aiemsomboon and Sintunavarat [20] used Theorem 3 above to investigate a new type of stability for the radical quadratic functional equation of the form (3). We refer to $[21,22]$ for more results from the Brzdęk fixed-point method in the stability problems of various functional equations such as Drygas functional equations and the general linear equations. Also Kang [23] studied the stability problem for generalized quadratic radical functional equations by using Brzdęk’s fixed-point approach.

In this paper, we consider the radical $n$ th-degree functional equation of the form

$$
f\left(\sqrt[n]{x^{n}+y^{n}}\right)=f(x)+f(y)
$$


for all positive integers $n>0$ and give an application of Brzdęk's fixed-point method for the stability problem of the radical $n$ th-degree functional equation (16) (see [24-26] for the cases of $n=2,3,4$ of (16) with various approaches). As the radical quadratic functional equation (3), a function $f: \mathbb{R} \longrightarrow \mathbb{R}$ satisfies (16) if and only if it is of the form

$$
f(x)=a\left(x^{n}\right), \quad x \in \mathbb{R}
$$

with an additive function $a: \mathbb{R} \longrightarrow \mathbb{R}$. For more extensions and generalizations of the solutions to functional equations of this radical type (16) and a different type of the radical $n$ th-degree functional equation of the form $f\left(\sqrt[n]{x^{n}+y^{n}}\right)+$ $f\left(\sqrt[n]{\mid x^{n}-y^{n}} \mid\right)=2 f(x)+2 f(y)$, we refer to $[27,28]$.

The stability results in this article will be an improvement and generalization of the stability problem of the radical quadratic, cubic, and quartic functional equations like (3). Throughout this paper, $\mathbb{N}_{0}, \mathbb{N}$, and $\mathbb{R}_{+}$denote the set of nonnegative integers, the set of positive integers, and the set of nonnegative real numbers, respectively.

\section{Stability of the Radical $n$ th-Degree Functional Equation}

In this section, we will investigate the stability problems of the radical $n$ th-degree functional equation (16) as introduced earlier; i.e.,

$$
f\left(\sqrt[n]{x^{n}+y^{n}}\right)=f(x)+f(y)
$$

for a positive integer $n$ by using Brzdęk's fixed-point method; see Theorem 3 in the introduction.

Theorem 4. Let d be a complete metric in $\mathbb{R}$ which is invariant (i.e., $d(x+z, y+z)=d(x, y)$ for $x, y, z \in \mathbb{R})$. Assume that for each positive integer $n \in \mathbb{N}, h: \mathbb{R}_{+} \longrightarrow \mathbb{R}_{+}$is a function such that

$$
M_{0}:=\left\{m \in \mathbb{N}: s\left(m^{n}\right)+s\left(1+m^{n}\right)<1\right\} \neq \emptyset
$$

where

$$
\begin{aligned}
& s(l) \\
& \quad:=\inf \left\{r \in \mathbb{R}_{+}: h\left(l x^{n}\right) \leq r h\left(x^{n}\right) \text { for all } x \in \mathbb{R}\right\},
\end{aligned}
$$

for $l \in \mathbb{N}$. Also suppose that a function $f: \mathbb{R}_{+} \longrightarrow \mathbb{R}$ satisfies the inequality

$$
d\left(f\left(\sqrt[n]{x^{n}+y^{n}}\right), f(x)+f(y)\right) \leq h\left(x^{n}\right)+h\left(y^{n}\right)
$$

for all $x, y \in \mathbb{R}_{+}$. Then, there exists a unique radical nth-degree mapping $R: \mathbb{R}_{+} \longrightarrow \mathbb{R}$ such that

$$
d(f(x), R(x)) \leq s_{0} h\left(x^{n}\right)
$$

for all $x \in \mathbb{R}_{+}$, where

$$
s_{0}:=\inf \left\{\frac{1+s\left(m^{n}\right)}{1-s\left(m^{n}\right)-s\left(1+m^{n}\right)}: m \in M_{0}\right\} .
$$

Proof. Let $m \in \mathbb{N}$ be a positive integer. On taking $y=m x$ in the inequality (21), we will see easily that

$$
d\left(f\left(\sqrt[n]{\left(1+m^{n}\right) x^{n}}\right), f(x)+f(m x)\right) \leq c_{m}(x)
$$

where $c_{m}(x)=\left(1+s\left(m^{n}\right)\right) h\left(x^{n}\right)$ for all $x \in \mathbb{R}_{+}$. Now, let us define two operators $\mathscr{T}_{m}: \mathbb{R}^{\mathbb{R}_{+}} \longrightarrow \mathbb{R}^{\mathbb{R}_{+}}$and $\Lambda_{m}: \mathbb{R}_{+}^{\mathbb{R}_{+}} \longrightarrow$ $\mathbb{R}_{+}^{\mathbb{R}_{+}}$by

$$
\mathscr{T}_{m} \varepsilon(x):=\varepsilon\left(\sqrt[n]{\left(1+m^{n}\right) x^{n}}\right)-\varepsilon(m x)
$$

and

$$
\Lambda_{m} \mu(x):=\mu\left(\sqrt[n]{\left(1+m^{n}\right) x^{n}}\right)+\mu(m x)
$$

for all $x \in \mathbb{R}_{+}, \varepsilon \in \mathbb{R}^{\mathbb{R}_{+}}$(or a function $\varepsilon: \mathbb{R}_{+} \longrightarrow \mathbb{R}$ ), and $\mu \in \mathbb{R}_{+}^{\mathbb{R}_{+}}$, respectively. Then we note that for each $m \in \mathbb{N}$, $\Lambda=\Lambda_{m}$ as in Theorem 3 with

$$
\begin{aligned}
& f_{1}(x)=\sqrt[n]{\left(1+m^{n}\right) x^{n}} \\
& f_{2}(x)=m x
\end{aligned}
$$

for all $x \in \mathbb{R}_{+}$. Hence, (13) in Theorem 3 is satisfied by (26). With the properties of the metric $d$, two inequalities (24) and (25) imply that

$$
\begin{aligned}
d & \left(\mathscr{T}_{m} f(x), f(x)\right) \\
& =d\left(f\left(\sqrt[n]{\left(1+m^{n}\right) x^{n}}\right)-f(m x), f(x)\right) \leq c_{m}(x)
\end{aligned}
$$

and also we have

$$
\begin{aligned}
& d\left(\mathscr{T}_{m} \varepsilon(x), \mathscr{T}_{m} \mu(x)\right)=d\left(\varepsilon\left(\sqrt[n]{\left(1+m^{n}\right) x^{n}}\right)\right. \\
& \left.\quad-\varepsilon(m x), \mu\left(\sqrt[n]{\left(1+m^{n}\right) x^{n}}\right)-\mu(m x)\right) \\
& \quad \leq d\left(\varepsilon\left(\sqrt[n]{\left(1+m^{n}\right) x^{n}}\right), \mu\left(\sqrt[n]{\left(1+m^{n}\right) x^{n}}\right)\right) \\
& \quad+d(\varepsilon(m x), \mu(m x))=d\left(\varepsilon\left(f_{1}(x)\right), \mu\left(f_{1}(x)\right)\right) \\
& \quad+d\left(\varepsilon\left(f_{2}(x)\right), \mu\left(f_{2}(x)\right)\right)
\end{aligned}
$$

for all $x \in \mathbb{R}_{+}$and $\varepsilon, \mu \in \mathbb{R}^{\mathbb{R}_{+}}$. Thus, the metric $d$ satisfies (12) in Theorem 3. Let $m \in M_{0}$. We; then, note that

$$
\begin{aligned}
& \Lambda_{m} c_{m}(x)=c_{m}\left(\sqrt[n]{\left(1+m^{n}\right) x^{n}}\right)+c_{m}(m x) \\
& \quad=\left(1+s\left(m^{n}\right)\right)\left(h\left(\left(1+m^{n}\right) x^{n}\right)+h\left(m^{n} x^{n}\right)\right) \\
& \leq\left(1+s\left(m^{n}\right)\right)\left(s\left(1+m^{n}\right)+s\left(m^{n}\right)\right) h\left(x^{n}\right)
\end{aligned}
$$

for all $x \in \mathbb{R}_{+}$. Applying the mathematical induction, it is not hard to show that

$$
\begin{aligned}
& \Lambda_{m}^{k} c_{m}(x) \\
& \quad \leq\left(1+s\left(m^{n}\right)\right)\left[s\left(1+m^{n}\right)+s\left(m^{n}\right)\right]^{k} h\left(x^{n}\right)
\end{aligned}
$$


for all $x \in \mathbb{R}_{+}$and each $k \in \mathbb{N}$. Hence, for each $m \in M_{0}$ and $x \in \mathbb{R}_{+}$, we conclude that

$$
\begin{aligned}
c_{m}^{*}(x) & :=\sum_{j=0}^{\infty} \Lambda_{m}^{j} c_{m}(x) \\
& \leq\left(\frac{1+s\left(m^{n}\right)}{1-s\left(1+m^{n}\right)-s\left(m^{n}\right)}\right) h\left(x^{n}\right)
\end{aligned}
$$

where $\Lambda_{m}^{0} c_{m}(x)=c_{m}(x)$, which means it satisfies the inequalities (14) in Theorem 3. Therefore, Brzdęk's fixed-point method implies that

$$
T_{m}(x):=\lim _{k \rightarrow \infty} \mathscr{T}_{m}^{k} f(x)
$$

exists for each $m \in M_{0}$ and $x \in \mathbb{R}_{+}$, and we have

$$
d\left(f(x), T_{m}(x)\right) \leq c_{m}^{*}(x)
$$

for all $m \in M_{0}$ and $x \in \mathbb{R}_{+}$(refer to Theorem 3 in the introduction). By using the mathematical induction on $k \in$ $\mathbb{N}_{0}$, we will show that

$$
\begin{array}{r}
d\left(\mathscr{T}_{m}^{k} f\left(\sqrt[n]{x^{n}+y^{n}}\right), \mathscr{T}_{m}^{k} f(x)+\mathscr{T}_{m}^{k} f(y)\right) \\
\leq\left(s\left(1+m^{n}\right)+s\left(m^{n}\right)\right)^{k}\left(h\left(x^{n}\right)+h\left(y^{n}\right)\right)
\end{array}
$$

for all $x, y \in \mathbb{R}_{+}$and $m \in M_{0}$, where $\mathscr{T}_{m}^{0} f(x)=f(x)$. The case of $k=0$ follows from the inequality (24). Assume that it holds when $k=t$. By using the properties of $d$, we will see that

$$
\begin{aligned}
& d\left(\mathscr{T}_{m}^{t+1} f\left(\sqrt[n]{x^{n}+y^{n}}\right), \mathscr{T}_{m}^{t+1} f(x)+\mathscr{T}_{m}^{t+1} f(y)\right) \\
& =d\left(\mathscr{T}_{m}^{t} f\left(\sqrt[n]{\left(1+m^{n}\right)\left(x^{n}+y^{n}\right)}\right)\right. \\
& -\mathscr{T}_{m}^{t} f\left(\sqrt[n]{m^{n}\left(x^{n}+y^{n}\right)}\right) \\
& \left.\left.\mathscr{T}_{m}^{t} f\left(\sqrt[n]{\left(1+m^{n}\right) x^{n}}\right)\right)-\mathscr{T}_{m}^{t} f(m x)\right) \\
& \left.\left.\left.+\mathscr{T}_{m}^{t} f\left(\sqrt[n]{\left(1+m^{n}\right) y^{n}}\right)\right)-\mathscr{T}_{m}^{t} f(m y)\right)\right) \\
& \leq d\left(\mathscr{T}_{m}^{t} f\left(\sqrt[n]{\left(1+m^{n}\right)\left(x^{n}+y^{n}\right)}\right)\right. \\
& \left.\left.\left.\mathscr{T}_{m}^{t} f\left(\sqrt[n]{\left(1+m^{n}\right) x^{n}}\right)\right)+\mathscr{T}_{m}^{t} f\left(\sqrt[n]{\left(1+m^{n}\right) y^{n}}\right)\right)\right) \\
& +d\left(\mathscr{T}_{m}^{t} f\left(\sqrt[n]{m^{n}\left(x^{n}+y^{n}\right)}\right)\right. \\
& \left.\left.\left.\mathscr{T}_{m}^{t} f(m x)\right)+\mathscr{T}_{m}^{t} f(m y)\right)\right) \leq\left(s\left(1+m^{n}\right)\right. \\
& \left.+s\left(m^{n}\right)\right)^{t}\left[h\left(\left(1+m^{n}\right) x^{n}\right)+h\left(\left(1+m^{n}\right) y^{n}\right)\right. \\
& \left.+h\left(m^{n} x^{n}\right)+h\left(m^{n} y^{n}\right)\right] \leq\left(s\left(1+m^{n}\right)\right. \\
& \left.+s\left(m^{n}\right)\right)^{t+1}\left(h\left(x^{n}\right)+h\left(y^{n}\right)\right)
\end{aligned}
$$

for all $x, y \in \mathbb{R}_{+}$. Letting $k \longrightarrow \infty$ in the inequality (35), we may obtain the following equality:

$$
T_{m}\left(\sqrt[n]{x^{n}+y^{n}}\right)=T_{m}(x)+T_{m}(y)
$$

for all $x, y \in \mathbb{R}_{+}$and $m \in M_{0}$. For each $m \in M_{0}$, the mapping $T_{m}$ is a solution of the radical $n$ th-degree functional equation; that is,

$$
R(x)=R\left(\sqrt[n]{\left(1+m^{n}\right) x^{n}}\right)-R(m x)
$$

for all $x \in \mathbb{R}_{+}$. Let $L>0$ be constant. Then, the mapping $R: \mathbb{R}_{+} \longrightarrow \mathbb{R}$ satisfying

$$
d(f(x), R(x)) \leq \operatorname{Lh}\left(x^{n}\right)
$$

for all $x \in \mathbb{R}_{+}$should be equal to $T_{m}$ for each $m \in M_{0}$. Let $m_{0} \in M_{0}$ be fixed and $R: \mathbb{R}_{+} \longrightarrow \mathbb{R}$ satisfy the inequality (39). We, then, note that

$$
\begin{aligned}
d( & \left.R(x), T_{m_{0}}(x)\right) \\
& \leq d(R(x), f(x))+d\left(f(x), T_{m_{0}}(x)\right) \\
& \leq\left(L+\frac{1+s\left(m_{0}^{n}\right)}{1-s\left(1+m_{0}^{n}\right)-s\left(m_{0}^{n}\right)}\right) h\left(x^{n}\right) \\
& \leq h\left(x^{n}\right) L_{0} \sum_{j=0}^{\infty}\left(s\left(1+m_{0}^{n}\right)+s\left(m_{0}^{n}\right)\right)^{j}
\end{aligned}
$$

where $L_{0}=\left(1-s\left(1+m_{0}{ }^{n}\right)-s\left(m_{0}{ }^{n}\right)\right) L+\left(1+s\left(m_{0}{ }^{n}\right)\right)$ (the case $h(x)=0$ is trivial, so we may exclude it here). Observe that $R$ and $T_{m_{0}}$ are solutions for (38) for each $m_{0} \in M_{0}$. Now, we will show that for each $l \in \mathbb{N}_{0}$,

$$
\begin{aligned}
& d\left(R(x), T_{m_{0}}(x)\right) \\
& \quad \leq h\left(x^{n}\right) L_{0} \sum_{j=l}^{\infty}\left[s\left(m_{0}^{n}\right)+s\left(1+m_{0}^{n}\right)\right]^{j}
\end{aligned}
$$

for all $x \in \mathbb{R}_{+}$. To show this, we will use the mathematical induction, again. The case $l=0$ follows from the previous inequality. Assume that it holds when the case $l \in \mathbb{N}_{0}$. Now, $m, m_{0} \in M_{0}$; (37) and (38) imply that 


$$
\begin{aligned}
& d\left(R(x), T_{m_{0}}(x)\right)=d\left(R\left(\sqrt[n]{\left(1+m_{0}^{n}\right) x^{n}}\right)\right. \\
& \left.-R\left(m_{0} x\right), T_{m_{0}}\left(\sqrt[n]{\left(1+m_{0}^{2}\right) x^{n}}\right)-T_{m_{0}}\left(m_{0} x\right)\right) \\
& \leq d\left(R\left(\sqrt[n]{\left(1+m_{0}^{n}\right) x^{n}}\right), T_{m_{0}}\left(\sqrt[n]{\left(1+m_{0}^{n}\right) x^{n}}\right)\right) \\
& +d\left(R\left(m_{0} x\right), T_{m_{0}}\left(m_{0} x\right)\right) \leq h\left(\left(1+m_{0}^{n}\right) x^{n}\right) \\
& \cdot L_{0} \sum_{j=l}^{\infty}\left[s\left(m_{0}^{n}\right)+s\left(1+m_{0}^{n}\right)\right]^{j}+h\left(m_{0}^{n} x^{n}\right) \\
& \cdot L_{0} \sum_{j=l}^{\infty}\left[s\left(m_{0}^{n}\right)+s\left(1+m_{0}^{n}\right)\right]^{j} \leq\left(s\left(m_{0}^{n}\right)\right. \\
& \left.+s\left(1+m_{0}^{n}\right)\right) h\left(x^{n}\right) L_{0} \sum_{j=l}^{\infty}\left[s\left(m_{0}^{n}\right)+s\left(1+m_{0}^{n}\right)\right]^{j} \\
& =h\left(x^{n}\right) L_{0} \sum_{j=l+1}^{\infty}\left[s\left(m_{0}^{n}\right)+s\left(1+m_{0}^{n}\right)\right]^{j} .
\end{aligned}
$$

Hence, the inequality (41) holds whenever $l \in \mathbb{N}_{0}$. Letting $l \longrightarrow \infty$ in the inequality (41), we have

$$
R=T_{m_{0}}
$$

where $m_{0} \in M_{0}$. This means that $T_{m}=T_{m_{0}}$ for each $m \in M_{0}$. Hence, we get that

$$
d\left(f(x), T_{m_{0}}(x)\right) \leq \frac{1+s\left(m^{n}\right)}{1-s\left(1+m^{n}\right)-s\left(m^{n}\right)} h\left(x^{n}\right)
$$

for all $m \in M_{0}$ and $x \in \mathbb{R}_{+}$. Thus, we may conclude that the inequality (22) holds with $R:=T_{m_{0}}$ and also the uniqueness follows from the equality (43).

Let us give a generalized classical Cauchy-difference-type stability of the radical $n$-th degree functional equation (16) from Theorem 4.

Corollary 5. Let $n$ be a positive integer and $h: \mathbb{R}_{+} \longrightarrow(0, \infty)$ a mapping such that

$$
\lim _{k \rightarrow \infty} \inf \sup _{x \in \mathbb{R}_{+}} \frac{h\left(k^{n} x^{n}\right)+h\left(\left(1+k^{n}\right) x^{n}\right)}{h\left(x^{n}\right)}=0 .
$$

Suppose that $f: \mathbb{R}_{+} \longrightarrow \mathbb{R}$ satisfies

$$
\left.d\left(\sqrt[n]{x^{n}+y^{n}}\right), f(x)+f(y)\right) \leq h\left(x^{n}\right)+h\left(y^{n}\right)
$$

for all $x, y \in \mathbb{R}_{+}$. Then, there exists a unique radical nth-degree functional equation $R: \mathbb{R}_{+} \longrightarrow \mathbb{R}$ such that

$$
d(f(x), R(x)) \leq h\left(x^{n}\right)
$$

for all $x \in \mathbb{R}_{+}$.
Proof. By the definition $s(m)$ as in Theorem 4, we will see that

$$
\begin{aligned}
s\left(m^{n}\right) & \leq \sup _{x \in \mathbb{R}_{+}} \frac{h\left(m^{n} x^{n}\right)}{h\left(x^{n}\right)} \\
& \leq \sup _{x \in \mathbb{R}_{+}} \frac{h\left(m^{n} x^{n}\right)+h\left(\left(1+m^{n}\right) x^{n}\right)}{h\left(x^{n}\right)}
\end{aligned}
$$

and

$$
\begin{aligned}
s\left(1+m^{n}\right) & \leq \sup _{x \in \mathbb{R}_{+}} \frac{h\left(\left(1+m^{n}\right) x^{n}\right)}{h\left(x^{n}\right)} \\
& \leq \sup _{x \in \mathbb{R}_{+}} \frac{h\left(m^{n} x^{n}\right)+h\left(\left(1+m^{n}\right) x^{n}\right)}{h\left(x^{n}\right)}
\end{aligned}
$$

These inequalities imply that

$$
\begin{aligned}
& s\left(m^{n}\right)+s\left(1+m^{n}\right) \\
& \quad \leq 2 \sup _{x \in \mathbb{R}_{+}} \frac{h\left(m^{n} x^{n}\right)+h\left(\left(1+m^{n}\right) x^{n}\right)}{h\left(x^{n}\right)}
\end{aligned}
$$

for all $x \in \mathbb{R}_{+}$. Now, for each $m \in \mathbb{N}$, let

$$
a_{m}:=\sup _{x \in \mathbb{R}_{+}} \frac{h\left(m^{n} x^{n}\right)+h\left(\left(1+m^{n}\right) x^{n}\right)}{h\left(x^{n}\right)}
$$

for each $x \in \mathbb{R}_{+}$. By our assumption, it is a sequence $\left\{a_{m}\right\}$ with subsequence $\left\{a_{m_{k}}\right\}$ such that $\lim _{k \rightarrow \infty} a_{m_{k}}=0$; that is,

$$
\lim _{k \rightarrow \infty} \sup _{x \in \mathbb{R}_{+}} \frac{h\left(m_{k}^{n} x^{n}\right)+h\left(\left(1+m_{k}^{n}\right) x^{n}\right)}{h\left(x^{n}\right)}=0
$$

The inequalities (50) and (52) imply that

$$
\lim _{k \rightarrow \infty}\left[s\left(m_{k}^{n}\right)+s\left(1+m_{k}^{n}\right)\right]=0 ;
$$

that is, $\lim _{k \longrightarrow \infty} s\left(m_{k}{ }^{n}\right)=0$. Thus, we have

$$
\lim _{k \rightarrow \infty} \frac{1+s\left(m_{k}^{n}\right)}{1-s\left(m_{k}^{n}\right)-s\left(1+m_{k}^{n}\right)}=1 .
$$

Letting $s_{0}=1$ as in Theorem 4 , the inequality (47) follows from the inequality (22).

\section{Data Availability}

There were no data used to support this study.

\section{Conflicts of Interest}

The authors declare that they have no conflicts of interest regarding the publication of this paper.

\section{Authors' Contributions}

All authors contributed equally to the writing of this paper. All authors read and approved the final manuscript. 


\section{Acknowledgments}

The present research was conducted by the research fund of Dankook University in 2018.

\section{References}

[1] S. M. Ulam, Problems in Modern Mathematics, Science Editions, Chapter 6, Wiley, New York, NY, USA, 1960.

[2] D. H. Hyers, "On the stability of the linear functional equation," Proceedings of the National Acadamy of Sciences of the United States of America, vol. 27, pp. 222-224, 1941.

[3] T. Aoki, "On the stability of the linear transformation in banach spaces," Journal of the Mathematical Society of Japan, vol. 2, pp. 64-66, 1950.

[4] D. G. Bourgin, "Classes of transformations and bordering transformations," Bulletin of the American Mathematical Society, vol. 57, no. 4, pp. 223-237, 1951.

[5] T. M. Rassias, "On the stability of the linear mapping in banach spaces," Proceedings of the American Mathematical Society, vol. 72, no. 2, pp. 297-300, 1978.

[6] P. W. Cholewa, "Remarks on the stability of functional equations," Aequationes Mathematicae, vol. 27, no. 1-2, pp. 76-86, 1984.

[7] S. Czerwik, "On the stability of the quadratic mapping in normed spaces," Abhandlungen aus dem Mathematischen Seminar der Universität Hamburg, vol. 62, pp. 59-64, 1992.

[8] Z. Gajda, "On stability of additive mappings," International Journal of Mathematics and Mathematical Sciences, vol. 14, no. 3, pp. 431-434, 1991.

[9] C. Park, "Generalized hyers-ulam stability of quadratic functional equations: a fixed point approach," Fixed Point Theory and Applications, vol. 2008, Article ID 493751, 9 pages, 2008.

[10] F. Skof, "Proprieta' locali e approssimazione di operatori," Rendiconti del Seminario Matematico e Fisico di Milano, vol. 53, no. 1, pp. 113-129, 1983.

[11] "Report of meeting: 16th international conference on functional equations and inequalities," in Annales Universitatis Paedagogicae Cracoviensis Studia Mathematica, vol. 14, pp. 163-202, Bedlewo, Poland, 2015.

[12] M. E. Eshaghi Gordji and M. Parviz, "On the Hyers-UlamRassias stability of the functional equation $f\left(\sqrt{x^{2}+y^{2}}\right)=$ $f(x)+f(y)$," Nonlinear Functional Analysis and Applications. An International Mathematical Journal for Theory and Applications, vol. 14, no. 3, pp. 413-420, 2009.

[13] S. Kim, Y. Cho, and M. E. Gordji, "On the generalized HyersUlam-Rassias stability problem of radical functional equations," Journal of Inequalities and Applications, vol. 2012, p. 186, 2012.

[14] J. A. Baker, "The stability of certain functional equations," Proceedings of the American Mathematical Society, vol. 112, no. 3, pp. 729-732, 1991.

[15] K. Ciepliński, "Applications of fixed point theorems to the Hyers-Ulam stability of functional equations-a survey," Annals of Functional Analysis, vol. 3, no. 1, pp. 151-164, 2012.

[16] J. Brzdęk, L. Cădariu, and K. Ciepliński, "Fixed point theory and the ulam stability," Journal of Function Spaces, vol. 2014, Article ID 829419, 16 pages, 2014.

[17] S. M. Jung, "A fixed point approach to the stability of isometries," Journal of Mathematical Analysis and Applications, vol. 329, no. 2, pp. 879-890, 2007.
[18] J. Brzdęk and K. Ciepliński, "A fixed point approach to the stability of functional equations in non-Archimedean metric spaces," Nonlinear Analysis: Theory, Methods \& Applications, vol. 74, no. 18, pp. 6861-6867, 2011.

[19] J. Brzdęk, "Stability of additivity and fixed point methods," Fixed Point Theory and Applications, vol. 2013, no. 285, 9 pages, 2013.

[20] L. Aiemsomboon and W. Sintunavarat, "On a new type of stability of a radical quadratic functional equation using Brzdęk's fixed point theorem," Acta Mathematica Hungarica, vol. 151, no. 1, pp. 35-46, 2017.

[21] L. Aiemsomboon and W. Sintunavarat, "Two new generalised hyperstability results for the drygas functional equation," Bulletin of the Australian Mathematical Society, vol. 95, no. 2, pp. 269-280, 2017.

[22] L. Aiemsomboon and W. Sintunavarat, "A note on the generalised hyperstability of the general linear equation," Bulletin of the Australian Mathematical Society, vol. 96, no. 2, pp. 263-273, 2017.

[23] D. Kang, "Brzdęk fixed point approach for generalized quadratic radical functional equations," Journal of Fixed Point Theory and Applications, vol. 20, 50 pages, 2018.

[24] Z. Alizadeh and A. G. Ghazanfari, "On the stability of a radical cubic functional equation in quasi- $\beta$-spaces," Journal of Fixed Point Theory and Applications, vol. 18, no. 4, pp. 843-853, 2016.

[25] Y. J. Cho, M. E. Gordji, S. S. Kim, and Y. Yang, "On the stability of radical functional equations in quasi- $\beta$-normed spaces," Bulletin of the Korean Mathematical Society, vol. 51, no. 5, pp. 1511-1525, 2014.

[26] I. EL-Fassi, "Approximate solution of radical quartic functional equation related to additive mapping in 2-banach spaces," Journal of Mathematical Analysis and Applications, vol. 455, no. 2, pp. 2001-2013, 2017.

[27] J. Brzdęk and J. Schwaiger, "Remarks on solutions to a generalization of the radical functional equations," Aequationes Mathematicae, vol. 92, no. 5, pp. 975-991, 2018.

[28] J. Brzdek, "Remarks on solutions to the functional equations of the radical type," Advances in the Theory of Nonlinear Analysis and its Applications, vol. 1, pp. 125-135, 2017. 


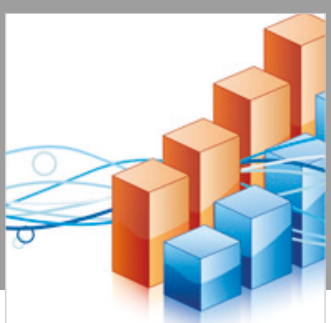

Advances in

Operations Research

\section{-n-m}
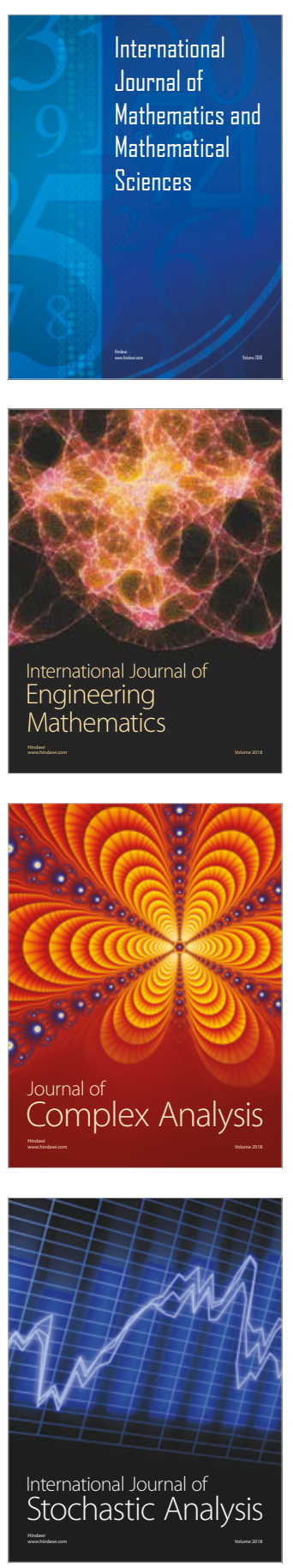
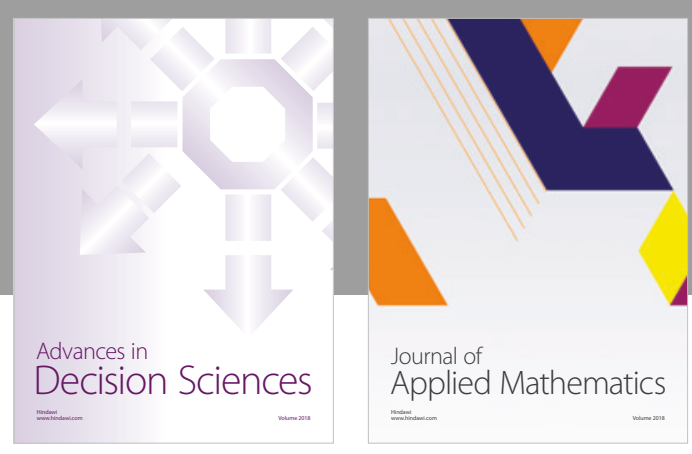

Journal of

Applied Mathematics
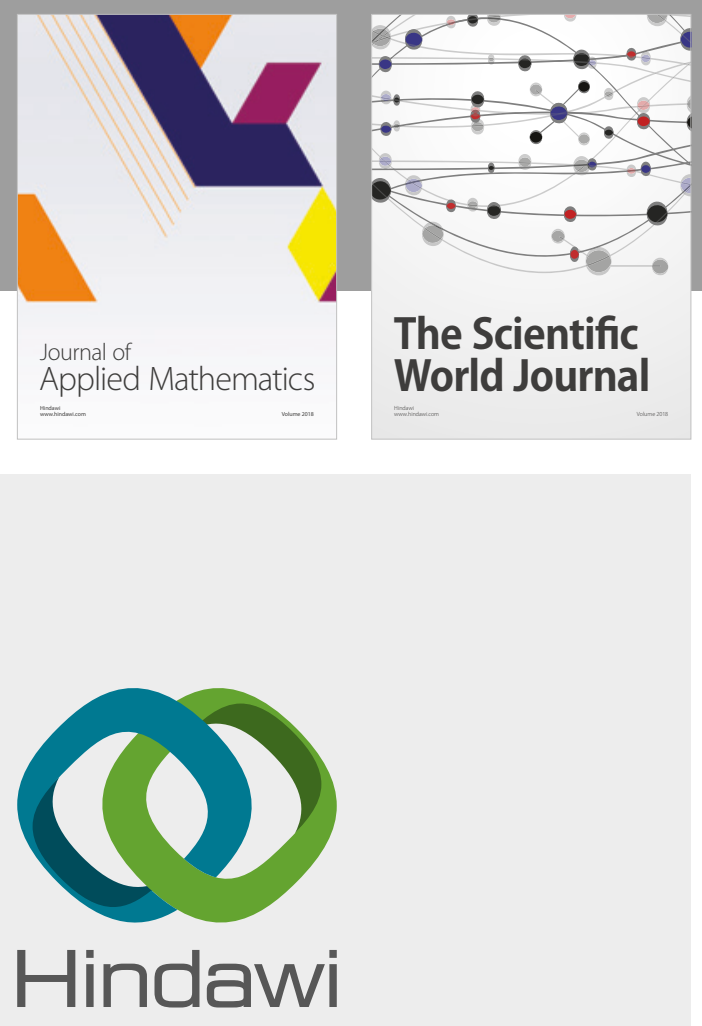

Submit your manuscripts at

www.hindawi.com

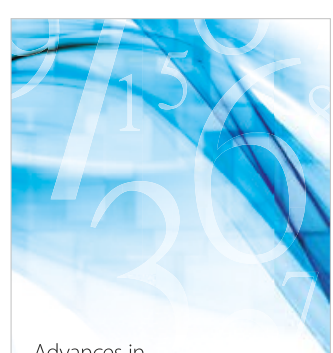

Advances in
Numerical Analysis
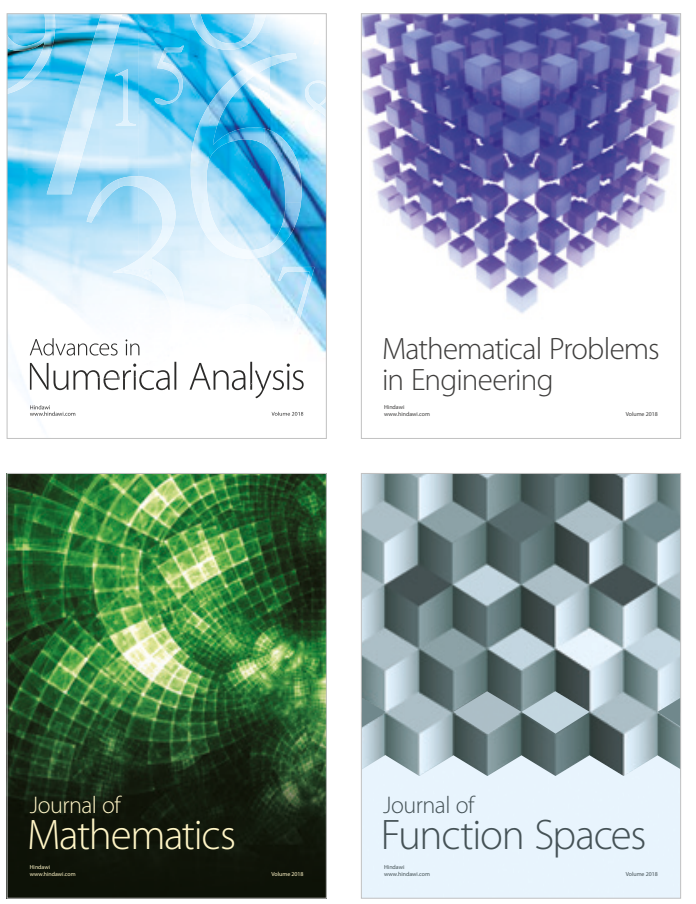

Mathematical Problems in Engineering

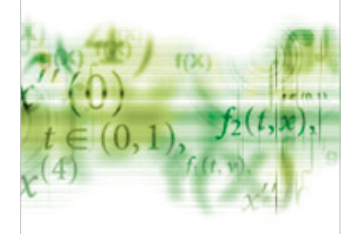

International Journal of

Differential Equations

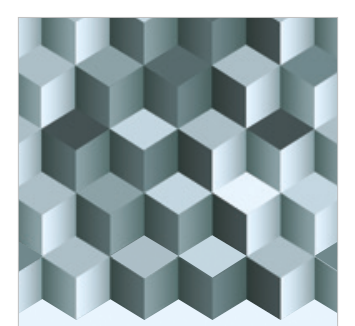

Journal of

Function Spaces
The Scientific

World Journal

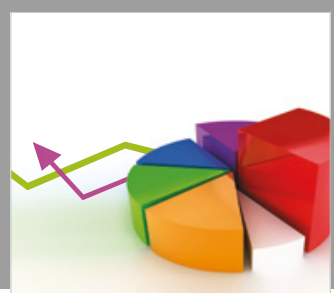

Journal of

Probability and Statistics
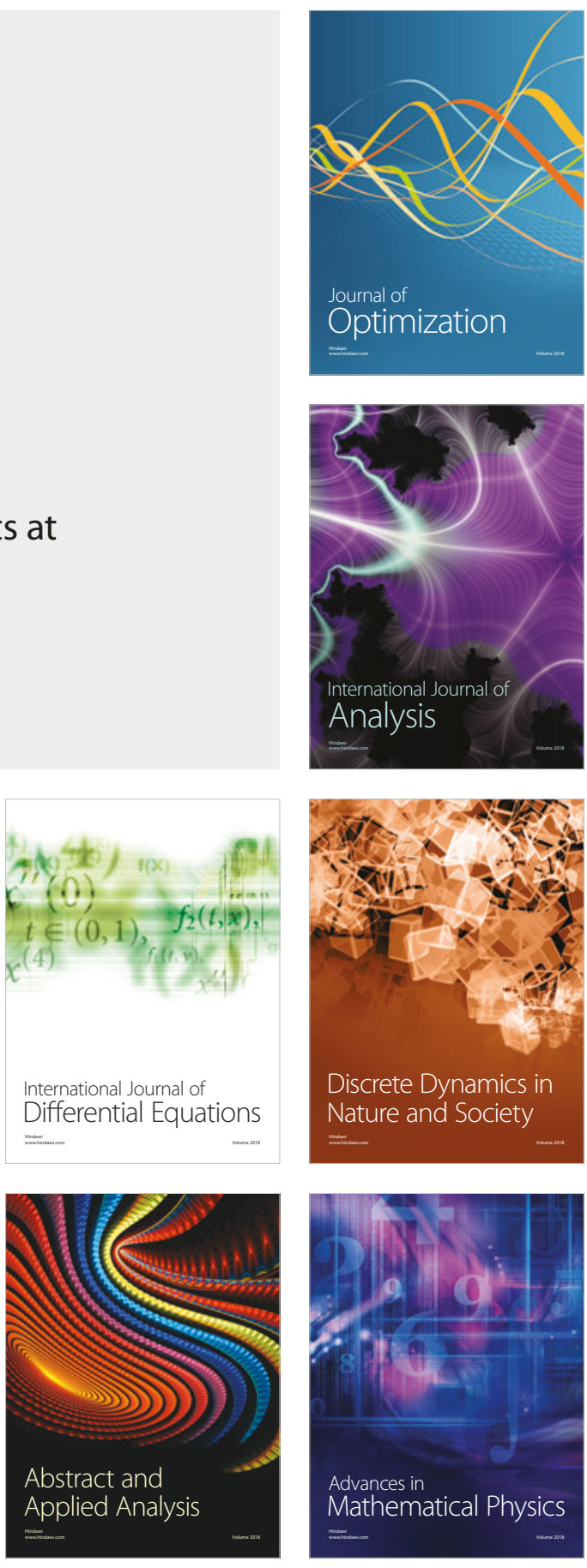